\title{
A RESPONSABILIDADE SOCIAL DAS EMPRESAS: \\ O CONTEXTO BRASILEIRO EM FACE DA AÇÃO CONSCIENTE OU DO MODERNISMO DO MERCADO?*
}

\author{
Carlos Nelson dos Reis
}

\begin{abstract}
RESUMO A responsabilidade social das empresas vem sendo questionada e impõe novos desafios gerenciais aos negócios, trazendo a emergência de medidas de enfrentamento para os problemas sociais, pois já não é mais possível conviver com o paradoxo de importantes inovações tecnológicas, de um lado, e a degradação da vida humana, de outro. A responsabilidade social das empresas no Brasil ainda é um desafio, uma vez que as ações de filantropia não têm contribuído efetivamente para a melhoria das condições de vida da sociedade e para a transformação da realidade social vigente. Este texto desenvolve uma problematização dessa questão, tendo como foco um conjunto de empresas brasileiras.
\end{abstract}

Palavras-chave: responsabilidade social; compromisso social; serviço social Código JEL: M, MOO, M1, M14, M00114

\section{CORPORATE SOCIAL RESPONSIBILITY: THE BRAZILIAN CONTEXT BEHIND A CONSCIOUS ACTION OR A MARKET MODERNISM?}

\begin{abstract}
The social responsibility of corporations has been challenged, requiring new answers by the business sector. As a consequence, social responsibility brings about the need of confronting the traditional measures with the paradox of increasing technical progress existing side-by-side with the process of degradation of human life. At present, the world capitalist society is demanding a revision of its main values, shifting its growth style to the sustained development pattern, the only
\end{abstract}

\footnotetext{
* Artigo recebido em 27 de abril de 2006 e aprovado em 12 de janeiro de 2007.

** Mestre em Economia e Administração de Negócios, Marketing e Contabilidade da Pontifícia Universidade Católica do Rio Grande do Sul, e-mail: cnelson@pucrs.br
} 
possibility of providing economic and social progress to the future generations. The present article deals with these issues, focusing on the actions of an ensemble of Brazilian enterprises.

Key words: social responsibility; social commitment; social work 


\section{INTRODUÇÃO}

No Brasil, a gravidade dos problemas sociais e a emergência de alternativas para o enfrentamento dessa realidade trazem à tona a discussão sobre a responsabilidade social das empresas. No setor privado, o movimento da responsabilidade social (RS) é composto por ambigüidades e controvérsias que, somadas às discussões sobre a situação de boa parte da população, cujas necessidades básicas ainda não estão sequer sendo supridas, tornam a RS das empresas brasileiras um desafio ainda maior.

No contexto mundial, o movimento da RS existe desde os anos 1960, mas, no Brasil, ele tomou forma e concretude nos anos 1980. Sua disseminação é lenta e carrega uma tradição histórica de filantropia assistencialista, portanto, trata-se de uma discussão em curso e com produção reduzida. Para efeitos dessa reflexão, sistematizaram-se alguns autores, sem a preocupação de pautar linhas de divergência e convergência a respeito do tema, e utilizaram-se informações estatísticas do IPEA, com o intuito de destacar algumas características do movimento no Brasil.

Nessa perspectiva, as referências que seguem caracterizaram: em primeiro lugar, as origens e a evolução da responsabilidade social das empresas, tendo por fim destacar o entendimento do seu significado; em segundo, uma síntese da evolução da ação social das empresas brasileiras; e, por fim, por meio de informações empíricas, em que estágio se encontravam as ações de RS nas empresas brasileiras como alternativa para a construção de uma sociedade com efetiva justiça social, econômica e sustentável.

\section{ORIGENS E EVOLUÇÃO DA RESPONSABILIDADE SOCIAL DAS EMPRESAS}

O movimento da responsabilidade social das empresas, cuja projeção nos EUA e na Europa aconteceu em meados dos anos 1960, passou a ser pauta na agenda dos empresários brasileiros, com mais visibilidade, ao longo dos anos 1990, incentivado pelo período de redemocratização e abertura econômica do País e pelos direitos conquistados com a Constituição Federal de 1988. No meio acadêmico, as reflexões sobre o tema iniciaram nos anos 1980, trazendo à tona as peculiaridades da RS em um país como o Brasil, cuja gravidade dos problemas sociais e a responsabilidade das empresas, seja 
no agravamento desses problemas, seja na contribuição para o seu enfrentamento, já não podiam mais passar despercebidos.

Uma das primeiras referências acadêmicas ao assunto, no Brasil, aponta a responsabilidade social das empresas como “(...) parte da premissa de que as organizações têm responsabilidade direta e condições de abordar os muitos problemas que afetam a sociedade (...) (Tomei, 1984: 189)”.

Nessa ótica, assim como as empresas têm responsabilidade pelos problemas sociais, também têm capacidade de utilizar ferramentas empresariais para seu enfrentamento. Oliveira reforça essa premissa, ao sustentar que a RS das empresas é a “(...) capacidade da empresa de colaborar com a sociedade, considerando seus valores, normas e expectativas para o alcance de seus objetivos"(Oliveira, 1984: 205), e acrescenta que ambas — empresa e sociedade - podem atingir seus objetivos. Essa definição revela a convergência de interesses das empresas e da sociedade, e veio ao encontro do momento político de abertura econômica do País, pois o ingresso de capitais norte-americano e europeu reforça e qualifica o debate sobre a RS das empresas.

A RS das empresas também deveria contemplar o atendimento às demandas da sociedade, na perspectiva de progresso, desenvolvimento humano e melhoria das condições de vida da população: “(...) o modelo de responsabilidade social deveria resultar de uma preocupação em se aliar o desenvolvimento econômico ao desenvolvimento de qualidade de vida" (Guimarães, 1984: 215). Nessa ótica, a questão do desenvolvimento econômico, humano e social foi contemplada como parte das responsabilidades das empresas.

Em uma perspectiva mais ampla, a RS das empresas é vista

(...) como um compromisso (...) com relação à sociedade e à humanidade em geral, e uma forma de prestação de contas do seu desempenho, baseada na apropriação e no uso de recursos que originalmente não lhe pertencem (Melo Neto e Froes, 1999: 84).

Sob esse prisma, as empresas consomem recursos da sociedade, renováveis ou não, mas que são patrimônio gratuito e coletivo da humanidade; logo, contraem "uma dívida social" (Melo Neto e Froes, 1999), sendo seu compromisso restituir à sociedade o que dela é absorvido, por meio de investimentos na área social e no meio ambiente. 
A evolução da rs das empresas pode ser dividida em três estágios, que, ao contemplarem permanentemente diferentes enfoques e públicos-alvo, envolvem todas as partes interessadas no processo de gestão social empresarial, através de ações gerenciais desenvolvidas para o enfrentamento das novas demandas sociais. Tais estágios são: “(...) $1^{\circ}$ estágio - exercício da gestão social interna (...) $2^{\circ}$ - exercício da gestão social externa (...) $3^{\circ}$ - exercício da gestão social cidadã (...)" (Melo Neto e Froes, 2001: 80-81).

Em relação ao primeiro, o exercício da gestão social interna tem o foco de atuação voltado para os funcionários e seus familiares, e refere-se a questões regulares da empresa, como saúde, segurança, qualidade no ambiente de trabalho e benefícios. O fato de o primeiro estágio ter como objetivo os funcionários gera questionamentos sobre os interesses envolvidos nessa decisão: se é o de aumentar a motivação, a satisfação e o comprometimento dos funcionários somente para incrementar a produtividade, tornando a gestão social interna um fim em si mesma, ou se visa a contemplar objetivos sociais mais amplos, de mudança de cultura.

O segundo estágio, relativo à gestão social externa, refere-se à sociedade, às comunidades e aos consumidores em questões como preservação do meio ambiente, impactos socioeconômico, político e cultural na sociedade, segurança e qualidade dos produtos. O terceiro estágio é o exercício da gestão social cidadã, que extrapola a comunidade e se estende à sociedade como um todo. As empresas inserem-se socialmente na comunidade, cooperando para o desenvolvimento e fomentando projetos locais e regionais, mediante ações de filantropia, incentivo à geração de empregos e estabelecimento de parcerias com o Governo e outras entidades, além da promoção de campanhas de conscientização social e de cidadania (Melo Neto e Froes, 2001). Mas a ação de filantropia, que, em realidade, apenas reproduz determinadas condições sociais vigentes ao invés de transformá-las, é uma questão presente na atuação social das empresas, e requer um repensar sobre sua efetividade.

Na gama de definições de responsabilidade social das empresas, também são utilizadas outras terminologias, como o conceito de cidadania empresarial, que parte de duas visões que se complementam, pois “(...) pressupõe uma concepção de empresa que é co-responsável pelo bem-estar da comunidade" (Melo Rico, 1998: 38), indo além do cumprimento de sua função 
econômica, ao assumir compromissos éticos que contribuam para a melhoria da qualidade de vida da comunidade, e sendo também definido como “(...) um conjunto de princípios e sistemas de gestão destinados à criação ou à preservação de valor para a sociedade (...)" (Soutello Alves, 2001: 4), ou seja, uma empresa que possa desenvolver métodos de gestão socialmente responsáveis e capazes de atender a diferentes anseios, não só das comunidades, mas de toda a sociedade.

A cidadania empresarial manifesta-se na cultura da empresa cidadã, que é aquela que "assume o compromisso e define políticas em relação a cada um de seus parceiros. Cultiva e pratica livremente um conjunto de valores (...)" (Martinelli, 1997: 83).

É cidadã porque preserva e respeita os interesses das partes com as quais tem relações diretas e indiretas, adotando uma postura proativa, que contribui para encaminhar soluções aos diversos problemas sociais, mobilizando recursos como informação, técnicas de gerenciamento, cultura de resultados, senso de prioridades, além de recursos financeiros, materiais e humanos, colocando-os à disposição da sociedade como fatores estratégicos para o desenvolvimento do bem comum. Mas a filantropia e a doação ainda são muito presentes no movimento da responsabilidade das empresas no Brasil. Nessa ótica, "a filantropia empresarial é um setor em crescente movimento e que representa algo novo não apenas no cenário organizacional, mas também no cenário da sociedade brasileira” (Melo Rico, 1998: 25), no qual os recursos privados do setor empresarial são utilizados para o atendimento das necessidades e dos interesses de fins públicos.

A filantropia empresarial, ao investir na sociedade, não está prestando favores ou doando benefícios. A nova ação social empresarial está procurando algum retorno, colaborar com o desenvolvimento do País, demonstrando que a iniciativa privada deve ser consciente, ter uma responsabilidade social em relação aos problemas que atingem a sociedade como um todo. A empresa cidadã é aquela que, além de cumprir sua função econômica, trabalha para a melhoria da qualidade de vida de toda a sociedade (Melo Rico, 1998: 29).

As empresas atuam nos espaços em que a ação social do Estado, por si só, é inconsistente para enfrentar graves problemas, como a situação de miséria e exclusão social que assola o País, seja por uma questão de ineficiência na 
aplicação de políticas sociais, seja por falta de recursos. Embora haja a compreensão de que a gestão de políticas e programas de erradicação da pobreza e das desigualdades sociais é ainda competência do Estado, a filantropia empresarial, por meio da doação e de investimentos em programas sociais, e articulada a ações do Estado e ao Terceiro Setor, pode contribuir para melhores resultados e maior abrangência dos programas, assim como para minimizar e enfrentar as demandas sociais.

Desse modo, percebe-se que a filantropia das empresas tem por objetivo possibilitar que projetos sociais de interesse público possam ser iniciados, e, para isso, é necessária a doação de recursos financeiros, tanto para o desenvolvimento de projetos próprios das empresas, apoiando projetos de ONGs, quanto para a criação de institutos e fundações, muitas vezes em associação com outras empresas. O que tem sido discutido na atualidade é que as empresas devem acompanhar os projetos e aperfeiçoar as ações, de modo a gerarem retorno em face dos investimentos realizados, não em lucros financeiros para si mesmas, mas para a sustentabilidade do projeto.

Por outro lado, o processo de globalização da economia faz com que, cada vez mais, as empresas se preocupem com a sustentabilidade de seu negócio e com sua imagem pública. "Portanto, o investimento em projetos sociais pode estar ligado à eficácia da produção e à lucratividade da empresa (...)" (Melo Rico, 1998: 37).

Mas, se o interesse econômico como um fim em si mesmo, muitas vezes, é o que desperta o interesse da empresa pela responsabilidade social e até pode ser o exercício inicial da sua atuação social, a “(...) pressão na sociedade civil como um todo, no sentido de 'cobrar' ações efetivas do empresariado para se envolver no processo de desenvolvimento social do País (Melo Rico, 1998: 37), também está despertando maior conscientização das empresas sobre seu papel no desenvolvimento humano e social do Brasil.

Assim, com base nas definições destacadas, é possível referir que o processo de implementação da responsabilidade social nas empresas brasileiras é muito recente e encontra desafios nas históricas peculiaridades dos agentes econômicos do País. Por exemplo, como a RS no Brasil não está expressa em caráter obrigatório, mas no de ajuda, no de colaboração ou de adesão, a ambigüidade da ação da empresa se faz presente a todo momento. Ou seja, os empresários e as instituições têm o pleno conhecimento do significado e 
da necessidade de atuarem nessa perspectiva, porém, na prática, essa compreensão não se evidência como um movimento consciente.

Nos termos desta reflexão, é fundamental destacar que o Segundo Setor ${ }^{1}$ tem papel preponderante na construção de uma sociedade mais justa, por meio de decisões e de ações socialmente responsáveis, transparentes e éticas, que preservem os interesses de todos os stakeholders, ${ }^{2}$ decisões essas que não suprimam dos indivíduos seu trabalho, seu sustento e o de sua família e uma vida digna. Isso é condição e requisito para a sustentabilidade social e econômica não apenas da sociedade, mas do próprio negócio.

No Brasil, as necessidades básicas de grande parcela da população ainda não estão sendo supridas. Questões relativas à sobrevivência, à fome, ao desemprego e à exclusão social, dentre outras, remetem as discussões acerca da responsabilidade social das empresas a um outro patamar. Os primórdios das discussões sobre responsabilidade social empresarial nos Estados Unidos e na Europa tratavam de problemas relativos ao meio ambiente e aos direitos dos consumidores. A realidade brasileira suscita outros questionamentos, muito mais intensos e urgentes de serem enfrentados e solucionados. Nesse sentido, a seguir, apresenta-se uma síntese histórica da ação social das empresas no País.

\section{SÍNTESE HISTÓRICA DA AÇÃO SOCIAL DAS EMPRESAS BRASILEIRAS}

Esta síntese tem por objetivo destacar os principais movimentos na formação da cultura de RS na sociedade brasileira. Para tanto, o critério metodológico utilizado fundamenta-se em destacar as principais organizações que ao longo do tempo foram surgindo e formando a cultura da RS no Brasil.

O histórico da atuação do setor privado brasileiro no contexto da RS tem registro desde 1961, quando a gravidade dos problemas sociais do País começou a preocupar alguns dirigentes cristãos de empresas brasileiras, que se uniram para fundar a Associação dos Dirigentes Cristãos de Empresas (ADCE), a qual, em 1977, se consolidou como uma entidade que, à luz do pensamento social-cristão, congregava empresários comprometidos com a transformação de sua empresa em um ambiente de melhoria pessoal, de modo a contribuir para uma sociedade solidária, justa, livre e humana. A ADCE foi pioneira no lançamento do debate sobre o Balanço Social, ${ }^{3}$ embo- 
ra sua publicação só tenha iniciado em 1984, com a empresa Nitrofértil, seguida, em 1992, pelo balanço do Banco do Estado de São Paulo (Banespa).

A Câmera Americana de Comércio de São Paulo, em 1982, instituiu o Prêmio ECO-Empresa e Comunidade, com a finalidade de reconhecer e divulgar esforços realizados por empresas que desenvolvessem projetos sociais para a promoção da cidadania em cinco categorias: cultura, educação, participação comunitária, educação ambiental e saúde. Em 1986, a Fundação Instituto de Desenvolvimento Empresarial e Social (FIDES), reunindo empresários de São Paulo, Minas Gerais, Bahia e Rio Grande do Sul, iniciou debates, eventos e atividades, em níveis nacional e internacional, sobre a responsabilidade social das empresas, com a missão de promover o diálogo e o entendimento em prol do desenvolvimento humano entre as várias instâncias que compunham a sociedade.

Essas iniciativas das empresas com fins públicos suscitaram questionamentos e reflexões sobre a abrangência e a competência do Segundo e do Terceiro Setor em face da área social: "Um terceiro setor, não lucrativo e não governamental, coexiste hoje, no interior de cada sociedade, com o setor público estatal e com o setor privado empresarial" (Fernandes, 1994: 11).

É importante destacar que se trata de um debate em curso e, portanto, inconcluso no que se refere às definições das respectivas competências. Para financiar sua atuação, o Terceiro Setor utiliza recursos provenientes de pessoas físicas e jurídicas, logo, também provenientes de empresas, para produzir bens e serviços públicos que respondam às necessidades coletivas sem gerar lucros, colocando em destaque inúmeras ações de indivíduos, grupos, instituições e, conseqüentemente, de empresas, todos com um mesmo objetivo: suprir carências sociais que afetam grande parcela da população.

Em São Paulo, em 1989, outro grupo de empresários, em parceria com a Câmara de Comércio de São Paulo e com outros agentes da sociedade que já vinham em processo de discussão e de troca de experiências sobre ações que pudessem contribuir para diminuir as desigualdades sociais do País, criou um subcomitê de filantropia, que, em 1995, resultou no Grupo de Instituições, Fundações e Empresas (GIFE) ${ }^{4}$ composto por instituições de origem privada. Seu objetivo era instrumentalizar melhor e qualificar tecnicamente as empresas, as fundações empresariais e os indivíduos que quisessem realizar investimentos sociais, por meio da difusão de conceitos e práti- 
cas de gestão que otimizassem melhor os recursos que seriam aplicados no desenvolvimento de ações de bem-estar e projetos sociais.

A proposta do GIFE é, ainda hoje, que as doações efetuadas pelas empresas o sejam de modo planejado e criterioso, e utiliza um conceito próprio, o investimento social privado, que é "(...) o uso planejado, monitorado e voluntário de recursos privados, provenientes de pessoas físicas ou jurídicas, em projetos sociais de interesse público" (GIFE, 2002: 12).

Através de maior planejamento e monitoramento dos recursos doados, estes devem reverter em reais benefícios à sociedade e, também, às próprias empresas, mediante a otimização dessa doação. O investimento social privado ainda é protagonizado pelos institutos ${ }^{5}$ ou fundações ${ }^{6}$ de origem empresarial, fundações comunitárias e familiares, todas constituídas como pessoa jurídica. As doações podem, inclusive, ser passíveis de deduções de incentivos fiscais. O Governo Federal autoriza as empresas tributadas em regime de lucro real a deduzirem até $2 \%$ do lucro operacional bruto em doações, desde que destinadas a entidades sem fins lucrativos, pela Lei das OCIPS, no 9.790/1999, ou a entidades declaradas como de utilidade pública, pela Lei no 35/1991. (GIFE, 2002).

Outra iniciativa de destaque do meio empresarial brasileiro é a Fundação Abrinq pelos Direitos da Criança e do Adolescente, fundada em 1990. A Abrinq é uma entidade de utilidade pública federal, mantida também por recursos de empresas, dentre outros, e não tem fins lucrativos. Sua missão é promover a defesa dos direitos e o exercício da cidadania das crianças e dos adolescentes, mobilizando e articulando a sociedade civil e o Poder Público, com atuação pautada pela ONU, pela Constituição Federal do Brasil de 1988 e pelo ECA de 1990. Apóia vários projetos, dentre eles o Programa Empresa Amiga da Criança e o Selo Empresa Amiga da Criança, iniciativas que buscam engajar empresas em uma atuação social, em especial na prevenção e na erradicação do trabalho infantil.

A partir de 1993, outras empresas passaram a publicar o Balanço Social, mas este obteve maior visibilidade nacional somente em 1997, por meio de uma parceria do Instituto Brasileiro de Análises Sociais e Econômicas (Ibase), uma organização não-governamental e sem fins lucrativos, criada em 1981, pelo Sociólogo Herbert de Souza, que, em parceria com o jornal $\mathrm{Ga}$ zeta Mercantil, lançou o Selo do Balanço Social. O Ibase representa um mar- 
co no Terceiro Setor, através da Campanha Ação da Cidadania contra a Miséria e pela Vida, que, em 1993, mobilizou todo o País contra a fome que assolava grande parcela de sua população.

Ultimamente, o Balanço Social já está sendo utilizado por muitas empresas em vários Estados do Brasil, embora tenha caráter obrigatório na cidade de São Paulo, para empresas privadas com mais de 100 funcionários, regulamentado pelo Projeto de Lei no 3.116/1997. Mas a obrigatoriedade de apresentação do Balanço Social é questionável, uma vez que é realizado não necessariamente por uma mudança de cultura e postura empresarial socialmente responsável, mas por uma obrigação expressa por lei, ainda que possa representar um primeiro exercício no processo de sensibilização e conscientização das empresas em face da área social.

Em 1994, foi fundado o Instituto Ayrton Senna, uma organização não governamental de origem empresarial cujo objetivo é oferecer condições de desenvolvimento humano a crianças e jovens do Brasil, promovendo o desenvolvimento pleno de seu potencial como pessoas e cidadãos por meio da criação, da implementação e da disseminação de métodos, técnicas e instrumentos de atuação social, denominados tecnologias sociais, em parceria com o Poder Público e o setor privado. Os recursos provêm de duas fontes: de alianças estratégicas com empresas e do licenciamento da marca e da imagem de Ayrton Senna e do Senninha.

Esse contexto de iniciativas empresariais e governamentais que foi descrito, seja através da criação de ONGs, seja desenvolvendo e apoiando projetos sociais próprios ou junto a comunidades, indica um movimento, uma mobilização e uma atuação social dos três setores da economia, que vêm desenvolvendo ações na tentativa de minimizar problemas de ordem social. Ao se retomar o conceito da responsabilidade social das empresas, é possível resgatar sua amplitude e sua essência, baseadas em valores éticos e universais mais amplos, indicativos de compromisso social, o qual, no Brasil, vem sendo tratado pelo Instituto Ethos ${ }^{7}$ de Responsabilidade Social.

O Ethos, criado em 1998, é uma associação de empresas interessadas em desenvolver suas atividades de forma socialmente responsável, em um permanente processo de avaliação e aperfeiçoamento, por meio do desenvolvimento de atividades de informação, conferências, debates e encontros, assistência técnica, comunicação, articulação e mobilização. Para o Ethos: 
Responsabilidade social é uma forma de conduzir os negócios da empresa de tal maneira que a torna parceira e co-responsável pelo desenvolvimento social. A empresa socialmente responsável é aquela que possui a capacidade de ouvir os interesses das diferentes partes (acionistas, funcionários, prestadores de serviços, fornecedores, consumidores, comunidade, Governo e meio ambiente) e consegue incorporá-los no planejamento de suas atividades, buscando atender às demandas de todos, e não apenas dos acionistas ou proprietários (disponível em: <http://www.ethos.org.br>).

Essa conceituação resgata a gestão da responsabilidade social das empresas em sua essência, o estabelecimento de um comportamento ético, transparente e socialmente responsável com os stakeholders, baseado em princípios e valores que norteiam as decisões, as ações e as relações, respeitando todas as partes interessadas, como funcionários, clientes, fornecedores, Governo, comunidade, acionistas, meio ambiente, concorrentes, dentre outros, e incorporando os diferentes interesses à gestão do negócio como orientação para a promoção do desenvolvimento social.

A missão do Ethos é disseminar a prática da responsabilidade social empresarial, ajudando as empresas a compreenderem e a incorporarem o conceito do comportamento socialmente responsável; implementar políticas e práticas que atendam a elevados critérios éticos, demonstrando aos acionistas a relevância de um comportamento socialmente responsável para alcançar o desenvolvimento sustentável e para o retorno, a longo prazo, dos investimentos realizados; assumir responsabilidades com todos aqueles que são impactados por suas atividades; identificar formas inovadoras e eficazes de atuar em parceria com as comunidades na construção do bem-estar comum; e prosperar, contribuindo para o desenvolvimento social, econômico e ambientalmente sustentável. ${ }^{8}$ Após essa rápida consideração sobre a evolução histórica da concepção de responsabilidade social pelo segmento empresarial brasileiro, são feitos alguns comentários sobre as evidências empíricas dessas atuações.

\section{EVIDÊNCIAS EMPÍRICAS DAS EMPRESAS BRASILEIRAS EM RS}

A importância desta análise não está na possível comprovação ou rejeição de pressupostos básicos da responsabilidade social nas empresas brasileiras, mas na compreensão de como esse movimento se insere em um País que 
convive com sérios problemas de ordem social, e, em face disso, se a atuação social das empresas pode realmente contribuir para o processo de transformação necessário e almejado. ${ }^{9}$ Inicia-se compondo uma síntese das principais concepções que permeiam o movimento da responsabilidade social das empresas brasileiras. As informações contidas no quadro 1 contemplam as diferentes concepções de RS no âmbito das empresas brasileiras.

Na prática, a responsabilidade social das empresas refere-se à adoção de um modelo de gestão de negócios no qual elas, estando conscientes de seu compromisso social de co-responsabilidade no desenvolvimento social e humano, ouvem, preservam e respeitam os interesses das diferentes partes, seus stakeholders, incorporando diferentes necessidades ao planejamento de seu negócio e operacionalizando-as por meio de suas decisões e atividades. Não restam dúvidas de que se trata de uma mudança significativa, pois, há poucas décadas, havia a idéia de que as empresas privadas deveriam prestar contas somente a seus acionistas e produzir lucros.

O conceito de ação social é o que, atualmente, mais reflete o modelo de atuação das empresas brasileiras que praticam a responsabilidade social, sendo definido pelo IPEA como aquelas ações não obrigatórias, realizadas pelas empresas por meio de doações ou projetos em áreas como assistência social e alimentação, dentre outras.

O IPEA pesquisou, aproximadamente, 780 mil empresas com um ou mais empregados, abrangendo todo o Brasil, iniciando a pesquisa em 1999. Os dados coletados resultaram em dois estudos: “Quem são, onde estão" e "A iniciativa privada e o espírito público". Para fins da análise proposta, neste item serão consideradas algumas informações relevantes, destacadas a seguir e apresentadas em tabelas, iniciando pela forma como as empresas pesquisadas atuam na área social. Apesar de serem informações já discutidas na literatura econômica, como se trata de uma discussão em curso, entendese a importância dos dados para qualificar a reflexão.

As informações contidas na tabela 1 demonstram que, embora com diferenças regionais na forma de realização da ação social para as comunidades, a doação de recursos é a mais utilizada em, aproximadamente, metade das empresas de todas as regiões, e, nas regiões Sul e Sudeste, tal doação direciona-se a organizações que executam projetos sociais. 
Quadro 1: Sistematização das diferentes concepções de RS nas empresas do Brasil

Responsabilidade social das empresas no Brasil

Ação social

- Atividades de assistência social, desde pequenas doações eventuais até grandes projetos estruturados (disponível em: $<$ http://www.ipea.gov.br>).

Investimento social privado

- O uso planejado, monitorado e voluntário de recursos privados em projetos sociais de interesse público (GIFE, 2002).

Filantropia empresarial

- Doação de recursos privados utilizados para atendimento de fins públicos (Melo Rico, 1998).

Governança corporativa

- Aperfeiçoamento da gestão organizacional para padrões socialmente responsáveis, a fim de que sejam sustentáveis no longo prazo (Soutello Alves, 2001).

Responsabilidade social das empresas

- Responsabilidade direta e condições de abordar os vários problemas que afetam a sociedade (Tomei, 1984).

- Preocupação em aliar o desenvolvimento econômico ao desenvolvimento de qualidade de vida (Guimarães, 1984).

- Forma de conduzir os negócios que torna a empresa coresponsável pelo desenvolvimento social e pela capacidade de ouvir os interesses das diferentes partes, conseguindo incorporá-los no planejamento de suas atividades (disponível em: <http://www.ethos.org.br>).

Fonte: Sistematização do autor.

Já na região Nordeste, $82 \%$ das doações de recursos são realizadas pelas empresas para o auxílio direto a pessoas carentes e às comunidades. No entanto, a partir do real significado de responsabilidade social das empresas, a doação de recursos não é a sua essência, mas a gravidade dos problemas brasileiros e a grande parcela da população que vive abaixo da linha de pobreza fazem com que a atuação social destas assim se externalize.

É importante frisar que a filantropia pode ser o processo inicial para a prática da responsabilidade social (Melo Neto e Froes: 2001), pois também é necessária e, portanto, não deve ser descartada ou ter seu valor diminuído. Porém, existem indicações de que os empresários brasileiros não possuem clareza do que é uma ação de caráter compensatório, emergencial, pontual e paternalista, pois esta, ao mesmo tempo que minimiza uma situação de extrema carência, colabora para reproduzir as mesmas condições sociais vigentes e estruturais de desigualdade e exclusão social, não contribuindo para a transformação social das condições de pobreza, da baixa qualidade de vida e para o processo de desenvolvimento social do País. As informações 
Tabela 1: Estrutura da atuação das empresas em ações para as comunidades segundo algumas regiões do Brasil, 1999-2001

\begin{tabular}{lccc}
\hline Especificação & (\%) Região Sudeste & (\%) Região Sul & (\%) Região Nordeste \\
\hline $\begin{array}{l}\text { Doação de recursos para organizações } \\
\text { que executam projetos sociais }\end{array}$ & 48 & 66 & 21 \\
\hline $\begin{array}{l}\text { Doação de recursos diretamente para } \\
\text { pessoas carentes ou comunidades }\end{array}$ & 44 & 64 & 82 \\
\hline \begin{tabular}{l} 
Fonte dos dados brutos: Pesquisa Ação Social do IPEA. Disponivel em: <http//www.ipea.gov.br/asocial>0. \\
\hline
\end{tabular}
\end{tabular}

Tabela 2: Distribuição das ações sociais para a comunidade segundo algumas regiões do Brasil, 1999-2001

\begin{tabular}{lccc}
\hline Especificação & Região Sudeste & Região Sul & Região Nordeste \\
\hline Assistência social & 57 & 66 & 50 \\
\hline Alimentação e abastecimento & 39 & 54 & 36 \\
\hline Educação e analfabetismo & 14 & 48 & 13 \\
\hline Qualificação profissional & 1 & 1 & 7 \\
\hline
\end{tabular}

Fonte dos dados brutos: Pesquisa Ação Social do IPEA. Disponível em: <http://www.ipea.gov.br/asocial>.

constantes na tabela 2 indicam a permanência do caráter assistencialista e compensatório na ação social das empresas.

A ação social das empresas configura-se no campo da assistência social, da alimentação e do abastecimento. O IPEA não define o que são as ações de assistência social, mas, a partir da Constituição de 1988, ela consta no item Seguridade Social, juntamente com previdência e saúde, passando de uma concepção de ajuda humanitária para uma de direito social. A aprovação da Lei Orgânica da Assistência Social (LOAS) tinha por objetivo justamente uma mudança de perspectiva na assistência social, qualificando-a como política pública e rompendo com a tradicional concepção da caridade e da benemerência, em direção à concepção de direito social e dever do Estado. Entretanto, a realidade brasileira, ao apelar para o protagonismo das empresas na área social, juntamente com o Estado e o Terceiro Setor, cria as condições para a reprodução do caráter humanitário e filantrópico, o que se confronta com o real significado de responsabilidade social e, principalmente, com os direitos sociais orientados pela Constituição.

Em questões relativas à educação e à qualificação profissional, embora com destaque na região Sul, os investimentos são incipientes em face das exigências impostas pelo mercado de trabalho e dos atuais níveis de desemprego tecnológico. A educação é a porta de entrada para o mundo do trabalho, e, mesmo sendo responsabilidade do Estado, as empresas têm ca- 
pacidade para contribuir no combate ao analfabetismo e na promoção de qualificação profissional (tabela 2).

Em realidade, a conscientização do empresariado sobre a gravidade da situação social que assola o País e sobre a necessidade de assumir uma atitude proativa e planejada na resolução dos problemas sociais implica as empresas assumirem um compromisso com a sociedade e o País, como cultura expressa através de um modelo de gestão de negócios socialmente responsável, que ultrapasse ações de doação, filantropia e assistência social. As informações das tabelas 3 e 4 possibilitam uma melhor compreensão do caráter filantrópico da ação social nas empresas brasileiras.

Os dados apontam que a ação social é, geralmente, responsabilidade do dono da empresa. Por um lado, o fato de o próprio empresário ser o responsável pela decisão e pela ação em si é positivo, e também demonstra sua responsabilidade individual em face dos graves problemas sociais. Por outro lado, pode representar que, por caber a ele a decisão, não é parte do planejamento da empresa, mas uma atitude pessoal e circunstancial (tabela 3).

A RS, como compromisso e responsabilidade expressa na cultura da empresa, requer planejamento para ser parte do modelo de gestão de negócios, e, embora deva perpassar a direção e todos os níveis hierárquicos, necessita de planejamento e execução elaborados por área competente, que pode ser a de recursos humanos, respeitando, é claro, o porte da empresa. Mas o fato de estar centrada no dono da empresa tem sua justificativa, conforme pode ser conferido na tabela 4 .

As informações indicam que, de modo geral, o que motiva a ação social das empresas é o caráter humanitário dos empresários brasileiros, que, possivelmente sensibilizados com a situação social do País, realizam doações financeiras principalmente para ações assistenciais e de alimentação. Essa forma compromete a sua avaliação, o seu aperfeiçoamento e a sua continuidade, tendo como resultado a negação da transformação social necessária (GIFE, 2002).

Um dos grandes desafios das empresas na área social é justamente incorporar a responsabilidade para além do discurso e inseri-la no planejamento e no orçamento das ações da empresa. A insignificante porcentagem de empresas em que a ação social está sob responsabilidade da área de RH confirma que, realmente, esta não faz parte do planejamento e da cultura da em- 
Tabela 3: Responsabilidade pela realização da ação social em algumas regiões do Brasil, 1999-2001

\begin{tabular}{lccc}
\hline Especificação & Região Sudeste & Região Sul & Região Nordeste \\
\hline Dono da empresa & 71 & 73 & 82 \\
\hline Área de RH & 1 & 14 & 12 \\
\hline Fonte dos dados brutos: Pesquisa Ação Social do IPEA. Disponível em: <http://www.ipea.gov.br/asocial>. &
\end{tabular}

Tabela 4: Motivos que levaram as empresas a realizarem ação social nas comunidades, em algumas regiões do Brasil, 1999-2001

\begin{tabular}{lccc}
\hline Motivos & (\%) Região Sudeste & (\%) Região Sul & (\%) Região Nordeste \\
\hline Motivos humanitários & 81 & 65 & 79 \\
\hline Complementar ação do Governo & 13 & 15 & 2 \\
\hline Melhorar a imagem da empresa & 15 & 43 & 64 \\
\hline Aumentar a satisfação dos empregados & - & 45 & 24 \\
\hline $\begin{array}{l}\text { Aumentar a produtividade e melhorar a } \\
\text { qualidade do trabalho }\end{array}$ & - & 44 & 14 \\
\hline Fonte dos dados brutos: Pesquisa Ação Social do IPEA. Disponível em: <http//www.ipea.gov.br/asocial>. &
\end{tabular}

presa, não está expressa em sua política e em seus valores, não tem orçamento previsto e planejamento compartilhado com todas as áreas da empresa, não há avaliação do seu impacto junto ao público-alvo, enfim, não é um modelo de gestão de negócios, mas uma ação social pontual, que, conforme já expressado, contribui para compensar, mas não diminuir, as desigualdades sociais do País (tabela 3).

A questão de as empresas complementarem a ação do Governo também deveria ser alvo de discussões. O enfrentamento dos problemas sociais do País precisa ser articulado entre os agentes econômicos - o Primeiro, o Segundo e o Terceiro Setor, cada qual assumindo a sua responsabilidade social como valor maior da sociedade. Os problemas estruturais que o País enfrenta - a fome, o desemprego, a exclusão social, dentre outros - não deveriam ser solucionados com medidas emergenciais, pontuais e por apelo à filantropia. $\mathrm{O}$ Estado não pode se ausentar de sua responsabilidade, pois os diversos problemas sociais do Brasil são uma situação estrutural e histórica, que demanda esforços integrados e responsabilidades compartilhadas em direção ao desenvolvimento de políticas macroeconômicas que possibilitem ao País crescimento econômico e desenvolvimento humano e social sustentável.

Mas, além de motivos humanitários, existem outros que levam os empresários a realizarem ação social: os interesses comerciais relacionados à 
estratégia empresarial, como a melhoria da imagem da empresa, o aumento da satisfação dos empregados, da qualidade e da produtividade do trabalho (tabela 4). Esses interesses são os que, possivelmente, justificam as informações constantes na tabela 5 .

Os dados da tabela 5 revelam, primeiramente, que existe um significativo percentual de empresas que não realizam ação social, seja para os empregados, seja para a comunidade. Em relação à atuação somente dos empregados, esta se apresenta muito mais expressiva do que a da comunidade, em uma proporção, no mínimo, três vezes maior na região Sul e muito mais significativa na região Nordeste. Direcionar ações para o público interno - funcionários e familiares — ou externo - comunidades — gera controvérsias em termos do que é prioritário e de quais os interesses envolvidos.

Nos dados da pesquisa do IPEA para a região Sudeste, em uma amostra de 1.315 entrevistados, manifestou-se o porquê de sua preferência por ações sociais internas:

O resultado esperado não se refere apenas à melhoria da qualidade de vida de seus empregados e familiares, mas, sobretudo, ao aumento do empenho, do comprometimento, da motivação e da produtividade (Melo Neto e Froes, 2001: 90).

Logo, interesses econômicos justificam a preferência de ações sociais por parte dos funcionários, o que corrobara a idéia de que falta conscientização por parte do empresariado do seu compromisso social no enfrentamento dos problemas sociais do País.

As informações das tabelas apresentadas apontam caminhos e reflexões sobre a importância e a necessidade de uma maior conscientização das empresas a respeito de sua responsabilidade na transformação da realidade social vigente. São necessários avanços que possibilitem melhor adequação

Tabela 5: Distribuição da ação social das empresas entre os empregados e a comunidade, em algumas regiões do Brasil, 1999-2001

\begin{tabular}{lccc}
\hline Especificação & (\%) Região Sudeste & (\%) Região Sul & (\%) Região Nordeste \\
\hline Empregados e comunidade & 45 & 40 & 52 \\
\hline Somente os empregados & 17 & 20 & 26 \\
\hline Somente a comunidade & 22 & 6 & 3 \\
\hline Não realizam ação social & 16 & 34 & 19 \\
\hline Fonte dos dados brutos:: Pesquisa Ação Social do IPEA. Disponível em: <http://www.ipea.gov.br/asocial>.
\end{tabular}

Fonte dos dados brutos:: Pesquisa Ação Social do IPEA. Disponível em: <http://www.ipea.gov.br/asocial>. 
entre a situação concreta de interesses econômicos da empresa e seu compromisso social.

Não existe consenso em até que ponto os objetivos econômicos das empresas podem ser compatíveis com os objetivos da sociedade, assim como não estão claras quais decisões as empresas podem e devem tomar para que realmente favoreçam fins sociais. Também não há consenso no quanto o empresário estará disposto e apto a realmente considerar as conseqüências sociais de seus atos junto a todas as partes interessadas. Entende-se que a questão maior a ser tratada é a dos valores éticos que norteiam e orientam as decisões e as ações tomadas pelos empresários e que perpassam todos os escalões da empresa e os stakeholders, o que pressupõe uma "mudança de postura, contribuindo para a reconstrução gradativa de valores substantivos" (Magalhães, 1984: 224), que, incorporados à gestão dos negócios das empresas, contribuam para o enfrentamento dos diversos problemas sociais e para um processo de transformação social, imprescindível ao restabelecimento da dignidade humana e à construção de uma sociedade mais justa $\mathrm{e}$ sustentável.

Nesse contexto, o ideal seria uma inversão de valores junto ao setor privado, priorizando as ações sociais não em detrimento do econômico, mas em sintonia com ele, mesmo que isso ainda não faça parte do pensamento e da cultura desse setor. Esse movimento, provavelmente, encetaria uma mudança de postura ética e moral.

A empresa é um negócio, e pode-se afirmar que o centro de interesse do investidor é o lucro, sendo os stakeholders o meio para alcançá-lo. Mas uma empresa é também uma organização social formada por grupos de pessoas que buscam a satisfação de suas necessidades. Assim, definir linhas de atuação que compatibilizem diferentes interesses, embora seja um grande desafio, é uma necessidade que o próprio mercado impõe. Em uma sociedade empobrecida, cada vez menos produtos e serviços serão consumidos, comprometendo a viabilidade econômica da empresa a longo prazo.

Mas, além dessa visão comercial, os dados apresentados apontam que motivos humanitários são os principais impulsos à ação social das empresas brasileiras, podendo representar um processo inicial de maior conscientização dos empresários sobre seu compromisso e sua responsabilidade perante os problemas sociais. A filantropia pode ser o caminho para o exercício da 
responsabilidade social, mas requer avanços dos empresários no sentido de mudanças: de cultura, de foco — de interno à empresa para a sociedade - , de uma postura comercial voltada a objetivos exclusivamente comerciais como um fim em si mesmo para uma postura voltada a interesses maiores da sociedade brasileira, transcendendo a função básica da empresa de geradora de riquezas, de cumprimento do que está expresso nas leis, para assumir seu papel como importante agente de desenvolvimento econômico, social e humano, uma cultura empresarial de responsabilidade social alicerçada no compromisso para a construção de uma sociedade mais justa e sustentável.

Da interpretação dos dados da pesquisa do IPEA, tem-se a importância da necessidade de uma mudança cultural nas empresas brasileiras, o que implicaria superação de interesses particulares na perspectiva do bem comum, por meio da maior conscientização dos empresários sobre seu compromisso social e do reconhecimento de que um sistema econômico, aliado a objetivos sociais maiores, pode ser a condição para a sustentabilidade social e, conseqüentemente, econômica, não só da sociedade, mas de seu negócio. O enfrentamento da questão social em todas as suas expressões deve ultrapassar o atual estágio de cumprimento das obrigações legais, de filantropia e de ação humanitária para uma atuação que provoque transformações sociais efetivas, por meio de atitudes éticas, transparentes e proativas em problemas estruturais, possibilitando tornar a sociedade brasileira mais justa e menos desigual e excludente.

O termo compromisso social é uma terminologia que recentemente vem sendo utilizada, e, embora ainda não conste uma definição científica e acadêmica, sua abrangência pode ser compreendida através de um paralelo com a filantropia, ambos conceitos que podem nortear a atuação social das empresas, ainda que em perspectivas distintas e, possivelmente, com resultados diferentes. As informações do quadro 2 possibilitam uma melhor compreensão da abrangência do compromisso social e da filantropia na atuação social das empresas.

Esse paralelo, ao diferenciar a filantropia do compromisso social em suas motivações, interesses, resultados, objetivos e impactos, aponta o porquê de a filantropia, mesmo não podendo ser descartada em face da gravidade dos problemas sociais do País, pouco contribui para a transformação da realidade social. Enquanto ela é humanitária, reativa e emergencial, resultado da 
decisão individual do dono da empresa, tendo como conseqüência sua gratificação pessoal, a concepção de compromisso social parte da noção de cidadania.

Logo, o compromisso social é um indicativo da responsabilidade das empresas exercida em seu sentido filosófico e de conscientização de seu papel na sociedade, devendo também estar incorporado aos seus valores e à sua missão, visando a alcançar metas e resultados por meio de ações em parceria com funcionários, Estado, comunidade e outros. O compromisso social impele-as à responsabilidade social na gestão dos negócios, como uma prática organizacional dotada de “(...) um sentido mais ético, humano e responsável” (Mcintosh et al., 2001: 8), de ação proativa no enfrentamento e na solução dos problemas sociais do País, contribuindo, assim, para um maior desenvolvimento econômico e social e para a construção de uma sociedade mais justa e sustentável.

Quadro 2: Paralelo entre filantropia e compromisso social

\begin{tabular}{ll}
\hline Filantropia & Compromisso Social \\
\hline As motivações são humanitárias. & $\begin{array}{l}\text { Atuação social para além de motivações altruístas, } \\
\text { entendida como responsabilidade. }\end{array}$ \\
\hline A participação é reativa e as ações, isoladas. & $\begin{array}{l}\text { A participação é proativa e as ações, mais integra- } \\
\text { das. }\end{array}$ \\
\hline
\end{tabular}

A relação com o público-alvo é de demandante e doador.
A relação com o público-alvo é de parceria, interdependência, compromisso e partilha de responsabilidades.

Busca-se dar transparência à atuação e multiplicar as iniciativas sociais.

Não há preocupação em associar a imagem da empresa à ação social.

Não há preocupação em relacionar-se com o Estado.

Relação de parceria com o Estado, para repartir responsabilidades e ampliar o alcance das ações de controle.

Os resultados resumem-se à gratificação pessoal de poder ajudar.

Os resultados são preestabelecidos; há preocupação com o cumprimento dos objetivos propostos; são elaborados projetos estruturados, comprometendo-se com sua continuidade.

A ação social decorre de uma opção pessoal dos dirigentes. A ação social vai além de uma opção individual dos
dirigentes. É incorporada à cultura na empresa, os
compromissos sociais são assumidos publicamente
e divulgados. A participação social é incorporada
aos valores e à missão institucional da empresa, par-
tilhada com os funcionários. 
Desenvolvimento econômico abrange a concepção de justiça social, pois, em uma nação em que a distribuição da riqueza não é eqüitativa, grande parcela da população não tem acesso à satisfação plena de suas necessidades humanas, aos direitos sociais e às condições de uma vida digna. Logo, o desenvolvimento econômico e o sustentável devem complementar-se e são condições para o desenvolvimento humano e social, que deve promover justiça e maior nível de bem-estar social.

As empresas, nesse processo, passariam de uma postura de espectadoras e, em parte, de colaboradoras da situação econômica e social atual para uma postura socialmente responsável, com decisões que contemplem o drama vivido pelo ser humano que, direta e indiretamente, delas depende, pois, como principal agente de desenvolvimento econômico, elas têm ingerência direta sobre os problemas sociais do País.

A discussão sobre a responsabilidade social das empresas, seja no Brasil, seja no mundo, deve extrapolar os problemas ambientais e abranger as questões elementares de sobrevivência e dignidade humana, conclamando os agentes econômicos a se comprometerem com o enfrentamento do paradoxo entre tecnologias avançadas e degradação da vida, que são contradições de um modelo econômico excludente, mas que já não podem mais passar despercebidas na vida em sociedade.

A responsabilidade social das empresas, por ser um tema relativamente novo, tanto no ambiente empresarial quanto no meio acadêmico, permite divergências conceituais e ambigüidades, gera controvérsias e ainda não tem uma aplicabilidade operacional consistentemente definida. É também tida como um modismo ou como mais uma forma de as empresas obterem vantagens competitivas. Mas o grande desafio, e que precisa estar claro, é que, em sua essência filosófica,

(...) é muito mais do que um conceito. Responsabilidade social [será] um valor pessoal e institucional que se reflete nas atitudes das empresas, dos empresários e de todos os seus funcionários e parceiros (Melo Neto e Froes, 2001: 179).

Logo, é mais do que um conceito, porque requer um novo modelo de relações sociais no seio da sociedade capitalista, assumido como um compromisso social de toda a humanidade na construção de uma sociedade mais justa, social e economicamente responsável e sustentável. 


\section{CONSIDERAÇÕES FINAIS}

Os processos de globalização e reestruturação do setor produtivo, que, pela introdução de novas tecnologias, vêm transformando o contexto econômico e social do capitalismo mundial e produzindo grandes avanços em todas as esferas da sociedade capitalista mundial, também trazem em seu bojo profundas transformações sociais, cujas conseqüências representam aumento dos problemas de ordem social em suas tradicionais e novas formas, atingindo países tanto desenvolvidos quanto em desenvolvimento e redimensionando os valores que regem a vida em sociedade.

Nesse contexto, em que já não é mais possível permanecer indiferente à constante degradação da vida humana, de valores éticos universais e do ambiente natural, a RS das empresas vem sendo questionada, pois elas são um importante agente de desenvolvimento econômico e, portanto, podem dar uma significativa contribuição à sociedade.

Este texto compõe uma sistematização realizada com base em uma revisão conceitual e visa a apontar várias questões, ambigüidades e controvérsias que permeiam as discussões da responsabilidade social das empresas nos meios tanto acadêmico quanto empresarial, em níveis mundial e nacional, assim como os interesses econômicos envolvidos e a necessidade de maior conscientização dos empresários sobre o tema.

O movimento da responsabilidade social das empresas, que ocorreu nos anos 1960, nos EUA, relacionado à degradação do meio ambiente e aos direitos dos consumidores, no Brasil, passou a ser pauta da agenda do setor privado a partir dos anos 1990, referindo-se à participação do setor empresarial no enfrentamento dos já tradicionais e novos problemas de ordem social, resultantes de um crescimento econômico desarticulado de um projeto de desenvolvimento econômico e social, e de transformações ocorridas no contexto econômico, no século XX, o que torna a prática da responsabilidade social no setor privado brasileiro um desafio ainda maior.

A responsabilidade social das empresas no Brasil pode ser definida como um modelo de comportamento ético e responsável na gestão das mesmas, que, em suas decisões e ações, resgatam valores e direitos humanos universais, preservando e respeitando interesses de todas as partes direta e indiretamente envolvidas no negócio, assim como os de toda a sociedade, em uma relação na qual todos obtêm vantagens. A prática da atuação social das empresas brasileiras ainda ocorre muito focada em ações de filantropia, reve- 
lando um caráter assistencialista, paternalista e emergencial que, embora minimize a situação de pobreza, miséria e exclusão social que degrada a vida humana no País, também contribui para a reprodução da situação social vigente.

A responsabilidade social incorporada às empresas como modelo de comportamento socialmente responsável inserido no planejamento dos negócios não se reduz a mais uma ferramenta de marketing, a um discurso empresarial ou a ações de filantropia. Ela deve resultar em um novo modelo de cultura de gestão de negócios, que pressuponha a tomada de decisões de maneira ética e correta, tornando a empresa co-responsável pelo processo de desenvolvimento de uma sociedade menos desigual, mais justa e com maiores condições de acesso da população a produtos e serviços, resultando em sustentabilidade da sociedade do ponto de vista social e econômico e também sustentabilidade econômica do próprio negócio.

Enfim, a responsabilidade social das empresas, em seu sentido mais amplo, significa agir com postura de compromisso com a vida em sociedade e com a dignidade humana, ser responsável e comprometido com os problemas sociais que assolam o País e o mundo, tomando atitudes concretas para enfrentá-los de modo a, efetivamente, melhorar as condições de vida, contribuindo para a sustentabilidade da sociedade e, como conseqüência, dos negócios.

Embora se constate que o movimento da responsabilidade social das empresas, no Brasil, ainda esteja em seu primeiro momento, dada a gravidade dos problemas sociais que o País precisa enfrentar, a responsabilidade social do setor privado vem redefinindo seus rumos e tendo uma importante e decisiva contribuição para o combate à questão social. Os avanços ainda não representam uma mudança cultural na maneira de conduzir os negócios, mas acredita-se que, pelas atuais discussões nos meios empresariais e acadêmicos, pode estar em curso um processo de ruptura dessa postura filantrópica na atuação social. Mas, para isso, é necessário que as empresas brasileiras realmente incorporem a responsabilidade social na gestão de seus negócios como um compromisso que resulte em uma cultura de co-responsabilidade no enfrentamento dos problemas e para o desenvolvimento social do País. Tal postura lhes legará uma ação consciente, em detrimento de agirem conforme um modernismo do mercado. 


\section{NOTAS}

1. Para essa classificação, este texto parte da seguinte compreensão: o Primeiro Setor é o Estado, o Segundo Setor, as empresas privadas, e o Terceiro Setor, as organizações não governamentais.

2. São entendidos como as partes interessadas nas atividades da empresa, tanto internas quanto externas, e configuram-se como: investidores, acionistas, empregados, clientes e fornecedores, dentre outros.

3. Em linhas gerais, trata-se de um instrumento estratégico para avaliar e multiplicar o exercício da responsabilidade social corporativa.

4. “Em 1995, quando um grupo de trabalho sobre 'cidadania empresarial', organizado em torno da Câmara de Comércio Brasil-EUA em São Paulo (Amcham) formaliza-se como Grupo de Instituições, Fundações e Empresas (GIFE), o termo 'terceiro setor' passou a ganhar notoriedade" (Falconer e Vilela, 2001: 30).

5. "No plano legal, os institutos empresariais correspondem a personalidades jurídicas denominadas associações, que são entidades criadas, necessariamente, a partir de idéias e esforços de mais de uma pessoa, em torno de um propósito que não tenha finalidade lucrativa" (GIFE, 2002: 17).

6. "As fundações empresariais são instituídas pelos sócios da empresa ou empresas envolvidas, ou por seus representantes legais, que fazem uma doação de bens do patrimônio de suas corporações para servir a uma causa predefinida" (GIFE, 2002: 17-18).

7. Ethos, palavra grega, significa estudo dos costumes, do caráter, da ciência da moral, do "espírito" de uma época, o tom determinante do sentimento de um povo ou de uma comunidade. De ethos deriva a ética como ciência do dever humano em seu sentido mais amplo, conjunto de regras de conduta do convívio entre as pessoas. Disponível em: $<$ http://www.ethos.org.br>.

8. Disponível em: <http://www.ethos.org.br >.

9. Essa análise tem como referência os dados relativos à Pesquisa Ação Social das Empresas $_{2}$ realizada pelo IPEA em 1999 e divulgada em 2000. Recentemente, em 2004, houve uma atualização, sem que, no entanto, houvesse alterações de porte nos resultados.

\section{REFERÊNCIAS BIBLIOGRÁFICAS}

ASHLEY, P. (2002) (org.). "Responsabilidade social corporativa e cidadania empresarial: uma análise conceitual comparativa”. Enanpad, set. 2000. Disponível em: <http: //www.gset. org.br>. Acesso em: 20 Mar.

(2002) Ética e responsabilidade social nos negócios. São Paulo: Saraiva.

BOWEN, HOWARD R. (1957) Responsabilidades sociais dos homens de negócios. Rio de Janeiro: Civilização Brasileira.

CEPAL (org.) (2002). Eqüidade, desenvolvimento e cidadania. Rio de Janeiro: Campus. 
CHURCHILL, G. A., PETER, J. P. (2000) Marketing: criando valor para os clientes. São Paulo: Saraiva.

DAFT, R. L. (1999) Administração. Rio de Janeiro: LTC.

DORNELLES, A. E. e (2001) “Exclusão social: velhos e novos pontos de uma agenda permanente”. In: C. N. dos Reis, (org.). América Latina: crescimento do comércio mundial e exclusão social. Porto Alegre: Dacasa Editora/Palmarinca, p. 253-275.

FALCONER, A. P., VILELA, R. (2001) Recursos privados para fins públicos: as grantmakers brasileiras. São Paulo: Petrópolis.

FERNANDES, R. C. (1994) Privado porém público: o Terceiro Setor na América Latina. Rio de Janeiro: Relume-Dumará.

FERREL, O. C. (2001) Ética empresarial: dilemas, decisões e casos. Rio de Janeiro: Reichmann \& Affonso.

GRAYSON, D., HODGES, A. (2002) Compromisso social e gestão empresarial. São Paulo: Publifolha.

GRUPO DE INSTITUTOS, FUNDAÇÕES E EMPRESAS - GIFE (2002) Investimento social privado: como iniciar um programa na sua empresa. São Paulo: Takano.

GUIMARÃES, H. W. M. (1984) "Responsabilidade social da empresa: uma visão histórica de sua problemática”. Revista de Administração de Empresas, São Paulo, v. 24, n. 4, p. 211 219 , out./dez.

IPEA. Pesquisa Ação Social das Empresas. (1999) Disponível em: <http: //www.ipea.gov.br/ asocial>. Acesso em 10 jun. 2002.

MAGALHÃES, I. M. M. (1984) "Responsabilidade social das empresas e a ação política dos indivíduos e da sociedade”. Revista de Administração de Empresas, Rio de Janeiro: Fundação Getúlio Vargas, v. 24, n. 4, p. 220-225, out./dez.

MARTINELLI, A. C. (1997) “Empresa cidadã: uma visão inovadora para uma ação transformadora”. In: E. IOSCHPE, (org.). Terceiro Setor: desenvolvimento social sustentado. Rio de Janeiro: Paz e Terra.

MCINTOSH et al. (2001) Cidadania Corporativa: estratégias bem-sucedidas para empresas responsáveis. Rio de Janeiro: Qualitymark.

MELO NETO, F. P. de, FROES, C. (2001) Gestão da responsabilidade social: o caso brasileiro. Rio de Janeiro: Qualitymark.

(1999) Responsabilidade social e cidadania empresarial: a administração do terceiro setor. Rio de Janeiro: Qualitymark.

MELO RICO, E. P. de (1998) “O empresariado, a filantropia e a questão social”. Revista Serviço Social e Sociedade, São Paulo, ano XIX, n. 58, p. 24-40, nov.

NICHELS, W. G., WOOD, M. B. (1999) Marketing: relacionamento, qualidade, valor. Rio de Janeiro: LTC.

OLIVEIRA, J. A. (1984) “Responsabilidade social em pequenas e médias empresas". Revista de Administração de Empresas, Rio de Janeiro: Fundação Getúlio Vargas, v. 24, n. 4, p. 203 210, out./dez. 
REIS, C. N. dos (2002) "Crescimento econômico e exclusão social no Brasil: velhos e novos problemas de uma agenda permanente”. Relatório Final. Porto Alegre: PUCRS/NEPES.

_ (2002) “Exclusão social: a multidimensionalidade de uma definição”. In: J. M. R. Mendes, e J. B. R. Desaulniers (orgs.). Textos \& Contextos: perspectivas da produção do conhecimento em Serviço Social. Porto Alegre : Edipucrs.

SEN, A. (2000) Desenvolvimento como liberdade. São Paulo: Companhia das Letras.

SOUTELLO ALVES, L. E. (2001) “Governança e cidadania empresarial”. Revista de Administração de Empresas, São Paulo: Fundação Getúlio Vargas, v. 41, n. 4, p. 78-86, out. dez.

TOMEI, P. (1984) “A responsabilidade social da empresa: análise quantitativa da opinião do empresariado nacional". Revista de Administração de Empresas, Rio de Janeiro, v. 24, n. 4, p. 189-202, out./dez. 